\title{
Induction of oestrus, recovery of gametes, and the timing of fertilization events in the opossum, Didelphis virginiana
}

\author{
J. C. Rodger* and J. M. Bedford \\ Reproductive Biology Laboratory, Department of Obstetrics and Gynecology, \\ Cornell University Medical College, New York, New York 10021, U.S.A.
}

\begin{abstract}
Summary. Of 14 lactating opossums maintained in laboratory conditions, 13 mated 4.7-8.5 days after removal of pouch young. The time between this removal and onset of receptive oestrus was negatively correlated with the age of the pouch young. Mating generally occurred between $24: 00$ and $06: 00 \mathrm{~h}$, with ovulation following between 13:00 and 16:00 h. Each animal ovulated a mean of 29.6 eggs (range 19-40), approximately equal numbers coming from both ovaries. Spermatozoa were absent from the uterus and were present only in the oviducts during the periovular period. Those not cleared by flushing (1-160 $\times 10^{3} /$ oviduct) remained incarcerated in isthmic crypts lined by a simple cuboidal epithelium. Spermatozoa in crypts were paired, separating or single. The progressively motile cells flushed from the oviduct presented a similar pattern to that in the crypts, about $30 \%$ of spermatozoa were firmly paired, the others either loosely associated or single. Only single spermatozoa attached to ova. Monospermic fertilization followed shortly after ovulation, and no supplementary spermatozoa were present in the perivitelline space. Deposition of the mucoid layer on the zona pellucida then began, often before incorporation of the fertilizing spermatozoon by the vitellus was complete. The oviducal epithelium was formed throughout by ciliated and secretory cells. In the ampulla and upper isthmus, the secretory cells produced the mucoid material which formed a thick coat over the egg surface. Ovum transit through the oviduct was rapid, in one animal eggs had reached the uterus and acquired a shell within $15-20 \mathrm{~h}$ of ovulation.
\end{abstract}

\section{Introduction}

In their pioneering studies of marsupial reproduction, Hill (1910) using the Australian eastern quoll (Dasyurus viverrinus) and Hartman $(1916,1919,1924 a)$ working with the Virginia opossum (Didelphis virginiana) noted the relatively rapid rate of ovum transport to the uterus, during which development proceeded only to the pronuclear stage and an extensive mucoid coat was deposited on the surface of the thin zona pellucida. However, despite this initial interest in marsupial conception and the many subsequent studies of different aspects of their reproduction, little has been learned of the way marsupial gametes interact at fertilization or of the controlling factors.

\footnotetext{
* Present address: Department of Immunology, John Curtin School of Medical Research, P.O. Box 334, Canberra, Australia 2601.
} 
The growth and differentiation of the gametes has been the subject of several reports. The marsupial oocyte and Graafian follicle are generally larger than their counterparts in eutherian ('placental') mammals, but they undergo the same biphasic growth. This biphasic pattern seems to be a therian feature since oocyte growth is continuous in the prototherian monotremes, as well as reptiles and birds (Lintern-Moore, Moore, Tyndale-Biscoe \& Poole, 1976; Lintern-Moore \& Moore, 1977). Marsupial spermatozoa have been studied and there are ultrastructural descriptions for those of several species (Harding, Carrick \& Shorey, 1979). In many marsupials, the spermatozoon undergoes marked morphological changes during epididymal transit which are far more extensive than those seen in eutherian mammals. These include: alteration in the pitch of the head relative to the tail, reshaping and condensation of the acrosome, the appearance of a mid-piece fibre network (Olson, 1975; Cummins, 1976; Harding et al., 1976; Temple-Smith \& Bedford, 1976) and, in American marsupials, pairing of spermatozoa. First reported as an epididymal event by von Korph (1902), the manner of sperm head membrane association at pairing has been described at the ultrastructural level for two opossum species (Phillips, 1970; Olson \& Hamilton, 1976; Olson, 1980; Temple-Smith \& Bedford, 1980). The functional significance of these features of sperm maturation, or to what extent they determine the mode of gamete interaction at fertilization, have not been addressed experimentally.

Two studies have examined aspects of sperm transport in the female tract. Spontaneous motility of the opossum tract occurs at oestrus but not after oestrus, and it was suggested that such contractions transported spermatozoa rapidly through the vaginal complex to the relatively distant cervices (Hartman, 1924b). In the tammar wallaby (Macropus eugenii), spermatozoa were present in appreciable numbers in the cervices, uteri and oviducts at about the time of ovulation, some $24 \mathrm{~h}$ after mating, but rarely in tracts sampled $6 \mathrm{~h}$ later (Tyndale-Biscoe \& Rodger, 1978).

The present paper describes the preliminaries to fertilization and related events in the Virginia opossum, while that of Rodger \& Bedford (1982) deals with separation of paired spermatozoa, and the main gamete interactions at fertilization.

\section{Materials and Methods}

The 7 male opossums (Didelphis virginiana) and 15 females carrying pouch young were purchased in March to May from a commercial supplier in North Carolina. The animals were housed in stainless steel cages $(55 \times 75 \times 60 \mathrm{~cm})$ on an absorbent litter, fed Lab Canine Diet No. 5006 (Purina) and water ad libitum. Removal of pouch young is commonly used to induce a predictable oestrus and ovulation in Australian marsupials (Renfree \& Tyndale-Biscoe, 1978), and has resulted in fertile matings of Virginia opossums in relatively large outdoor enclosures (New \& Mizell, 1972; New, Mizell \& Crockroft, 1977), and in small cages in an essentially outdoor environment (Jurgelski et al., 1974; Jurgelski \& Porter, 1974; Renfree, 1974; Feldman $\&$ Ross, 1975). This approach was used here to obtain natural mating of animals in a laboratory animal house $(12 \mathrm{~h}$ light $(06: 00-18: 00 \mathrm{~h}) / 24 \mathrm{~h})$.

Females were sedated with ketamine hydrochloride (Ketaset, Bristol Laboratories; 50 $\mathrm{mg} / \mathrm{kg}$ ) and the young were removed. Beginning on Day 4 after removal, each female was allowed periodic access to a male (see 'Results') in a long wooden cage $(40 \times 40 \times 245 \mathrm{~cm})$ divisible into two by a removable partition. The top was covered with wire mesh to permit observation of the animals. This introduction of male to female was repeated regularly, at least once in the morning and twice at night until mating was observed or was indicated by a vaginal smear containing spermatozoa. Copulation was estimated to have occurred half-way between the last sperm-free and the sperm-containing vaginal smears. The age of the removed young was determined on the basis of the mean of individual snout-rump measurements (Reynolds, 1952). 
The data on the age of the litters and the time from their removal to mating were subjected to correlation coefficient analysis and a regression line was drawn using conventional methods (Bishop, 1971).

Following detection of mating, females were examined by laparotomy 3-26 h later to establish the time of ovulation. The animals were sedated and then anaesthetized with pentobarbitone sodium (Nembutal: Abbott). Initially, the pentobarbitone was given via pouch veins (Jurgelski, 1974). However, as quite large total doses of pentobarbitone (at a rate of $60 \mathrm{mg}$ every 1-2 h) were well tolerated when given intramuscularly, this route was used in subsequent trials. It allowed easy induction and maintenance of anaesthesia, even for repeated manipulations over extended periods (up to $6 \mathrm{~h}$ ). At the end of each experiment, the animal was killed by intra-cardiac injection of pentobarbitone.

Laparotomy was performed via a mid-line incision extending from within the anterior half of the pouch forward. Examination of the ovaries required that the fimbria be lifted from a major portion of the ovarian surface. However, this unavoidable manipulation did not interfere subsequently with ovum pick-up. When the ovulatory status of an animal had been determined, the opossum was left intact for later laparotomy or an ovary or one side of the tract (ovary, oviduct, uterus and cervix) were removed. Preovulatory oocytes were obtained by pricking the surface of maturing ovarian follicles with a fine needle.

Ovaries and oviducts were removed at times covering the period from before ovulation to about $18 \mathrm{~h}$ after ovulation. The oviduct was extended by dissection to its full length (some 10 $\mathrm{cm}$ ) and the contents washed into a watch glass with Tyrode's solution (GIBCO) or Medium 199 with Earle's salts and glutamine (GIBCO) using a fine hand-drawn Pasteur pipette. Initial examination of the flushings with a dissecting microscope $(\times 70)$ revealed whether mucoid deposition around ova had begun and whether motile spermatozoa were present in the medium. Approximately half of each group of living ova were then examined closely by phase-contrast microscopy. Following this, they were fixed in acetic-alcohol and stained with $1 \%$ lacmoid in $45 \%$ acetic acid (Chang, 1952; Bedford, 1971). This method proved quite suitable for opossum ova. Polar bodies and female chromatin were identifiable, as were the tail and decondensing head of the fertilizing spermatozoon.

Haemocytometer counts were made of the number of paired and single spermatozoa present in oviducal flushings, and the total number of individual spermatozoa flushed from each oviduct was calculated.

Histological observations were performed on paraffin wax-embedded tissues which had been fixed for $24 \mathrm{~h}$ in Bouin's fluid. Sections were cut at $7 \mu \mathrm{m}$ and stained with Harris' haematoxylin and eosin, or one of the following mucopolysaccharide histochemical methods; periodic acid-Schiff (PAS; Pearse, 1968, p. 660), toluidine blue (Kramer \& Windrum; Pearse, 1968, p. 665), and alcian blue (1\% pH 2.5; Pearse, 1968, p. 673). Bouin-fixed tissue was also embedded in JB-4 medium (Polysciences Inc., Warrington, Pennsylvania). Sections $(3 \mu \mathrm{m})$ were cut of this plastic embedded tissue using glass knives on a Sorvall JB-4 microtome, and stained by the PAS method described above or Giemsa $(1 \cdot 5-2 \mathrm{~h})$ with haematoxylin as a nuclear stain. The methods used for electron microscopy were as described by Rodger \& Bedford (1982).

\section{Results}

\section{Induction of oestrus and detection of copulation}

Of the 14 females with firmly attached litters 13 mated naturally 4.7 to 8.5 days after removal of the young (19 March to 7 May) (Text-fig. 1). The time to mating after removal of young was negatively correlated with the age of the litter $(r=-0.71 ; P<0.01$; Text-fig. 1). The animal that did not mate cycled, as judged by vaginal smears, but spermatozoa were not detected and eventually it became anoestrous. A further animal received with two pouch young 
(approximate age: 80 days; 27 April) no longer attached to the nipples failed to mate at the expected first oestrus but onset of the subsequent oestrus was detected a month later by vaginal smears. An apparently normal mating occurred, and oocytes were recovered from the oviducts, but there were no spermatozoa in the tract.

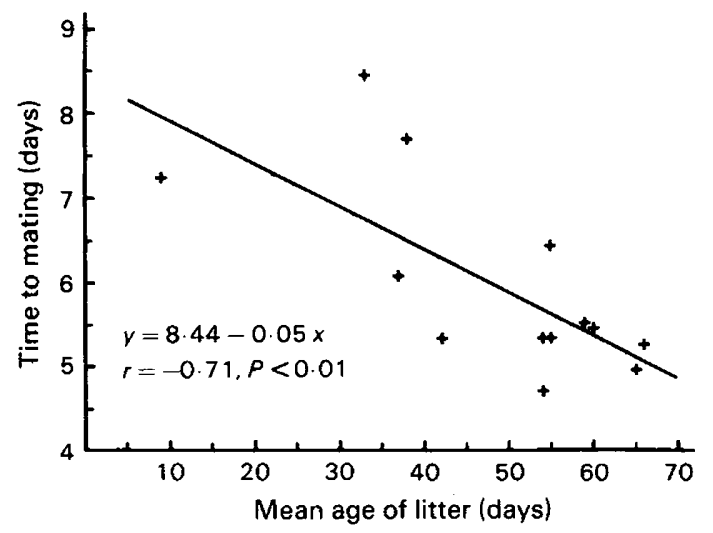

Text-fig. 1. The relationship between the time to mating, in the opossum Didelphis virginiana, and the age of the removed litter of pouch young.
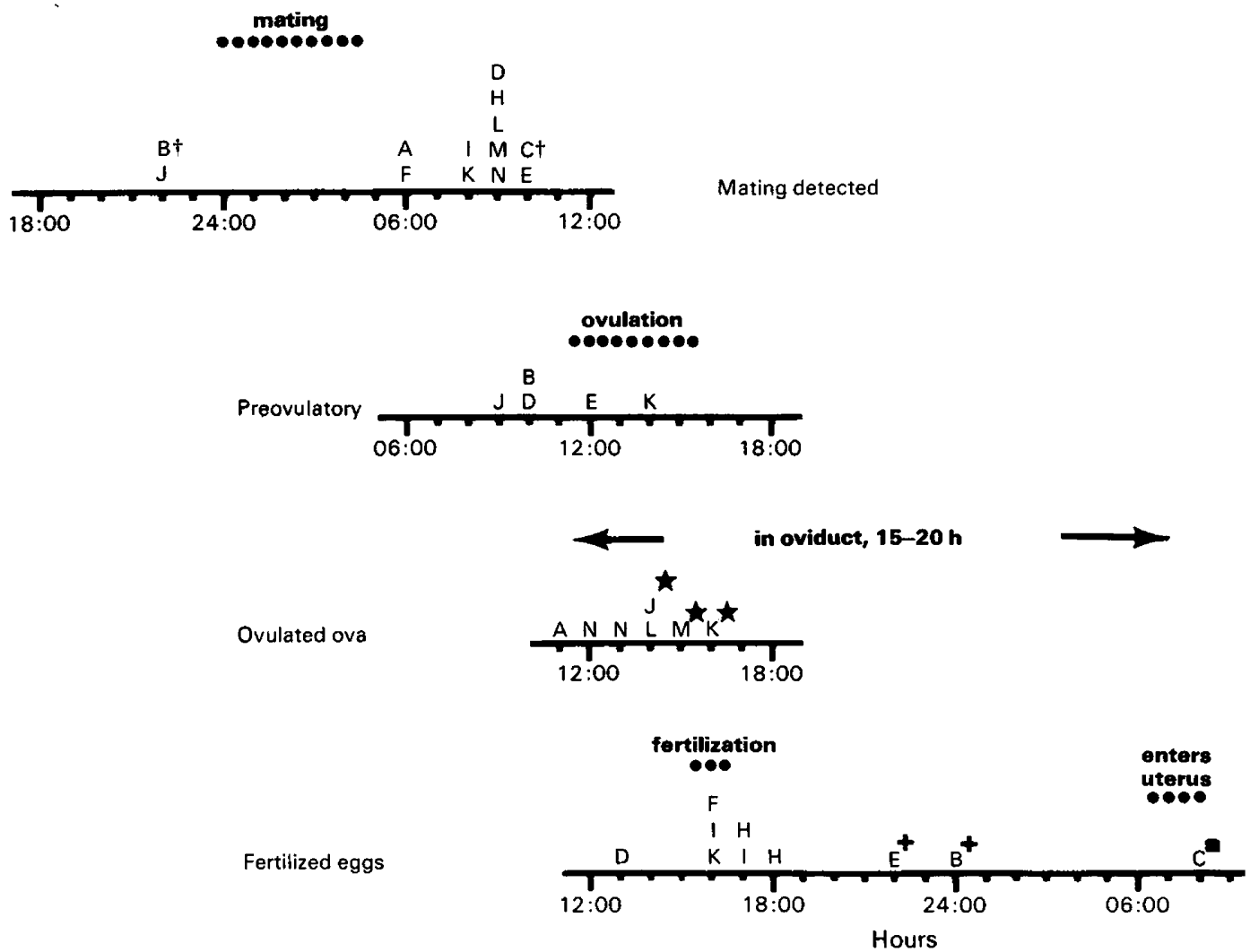

Text-fig. 2. Time of mating, ovulation, fertilization, and tubal transit in the opossum, Didelphis virginiana. $\mathbf{A}-\mathbf{N}=$ observations for individual animals. $\dagger=$ mating observed; in all other animals, copulation was indicated by spermatozoa in the vaginal smear. $\star=$ incomplete ovulation; $+=$ pronuclei present $\boldsymbol{\square}=2$-cell embryo. 
Mating was actually observed only twice, otherwise being deduced from spermatozoa in the vaginal smear (Text-fig. 2). The earliest instances of mating were a copulation observed at 22:00 $\mathrm{h}$, and one detected by vaginal smears between $20: 00 \mathrm{~h}$ and $22: 00 \mathrm{~h}$ on the day before ovulation. The latest instance was mating observed at 10:00 h on the day of ovulation in a female isolated from the male since 23:00 h the day before. In 7 of the 11 animals in which vaginal spermatozoa were detected in the morning (06:00-10:00 h), the animal had not mated when tested the previous night $(22: 00-24: 00 \mathrm{~h})$. Although the exact time of mating in these opossums was uncertain, it probably occurs in the early morning at least $12 \mathrm{~h}$ before ovulation which generally takes place between 13:00 and 16:00 h (see below).

\section{Recovery of spermatozoa and their distribution in the female tract (Table 1)}

The numbers of spermatozoa flushed from the oviduct varied considerably even in animals sampled over the periovular period (1-160 × 103\% oviduct; Table 1). The higher values probably indicate more clearly the actual total numbers of oviducal spermatozoa. The reason for the very low recovery on occasion was probably due to failure to remove many spermatozoa from the oviducal crypts. As shown in histological sections (Table 1; Pl. 1, Figs 1 and 2) or in thin section in the electron microscope (Pl. 2, Fig. 3), spermatozoa were always present in some crypts after flushing the oviduct. The two samples with the very lowest sperm numbers $\left(1\right.$ and $\left.5 \times 10^{3}\right)$ lacked paired spermatozoa entirely, a further indication that the oviducal crypts of these animals had not been adequately flushed.

Table 1. Distribution and state of spermatozoa in the female tract of the opossum, Didelphis virginiana, following natural mating

\begin{tabular}{|c|c|c|c|c|c|}
\hline \multirow[b]{2}{*}{ Stage } & \multirow[b]{2}{*}{ Animal } & \multirow{2}{*}{$\begin{array}{c}\text { Time } \\
\text { of } \\
\text { sample } \\
\text { (h) }\end{array}$} & \multicolumn{2}{|c|}{ Spermatozoa flushed from oviduct } & \multirow[b]{2}{*}{ Histological sections } \\
\hline & & & No. and motility & $\begin{array}{l}\text { Proportion } \\
\text { paired }\end{array}$ & \\
\hline Pre-ovulatory & $\begin{array}{l}\mathbf{J} \\
\mathbf{K}\end{array}$ & $\begin{array}{l}09: 00 \\
11: 00\end{array}$ & $\begin{array}{l}\text { Very few } \\
\text { Many very motile }\end{array}$ & $\overline{2 / 3}$ & $\begin{array}{l}\text { Crypts none } \\
\text { Many paired, some separating }\end{array}$ \\
\hline $\begin{array}{r}\text { Unfertilized } \\
\text { tubal ova }\end{array}$ & $\begin{array}{l}\text { A } \\
\text { N } \\
\text { N } \\
J^{*} \\
\text { L } \\
\text { M } \\
\text { K }\end{array}$ & $\begin{array}{l}11: 00 \\
12: 00 \\
13: 00 \\
14: 00 \\
14: 00 \\
15: 00 \\
16: 00\end{array}$ & $\begin{array}{l}\text { Many very motile } \\
9 \times 10^{3} \\
5 \times 10^{3} \\
- \\
160 \times 10^{3} \\
1 \times 10^{3 \dagger} \\
135 \times 10^{3}\end{array}$ & $\begin{array}{r}1 / 4 \\
6 \% \\
0 \% \\
-15 \% \\
0 \% \\
30 \% \\
\end{array}$ & $\begin{array}{l}\text { Many paired, some separating } \\
\text { None paired, a few single } \\
\text { Many paired, some separating }\end{array}$ \\
\hline Fertilized ova & $\begin{array}{l}\text { D } \\
\text { F } \\
\text { I } \\
\text { H } \\
\text { E } \\
\text { B } \\
\text { C }\end{array}$ & $\begin{array}{l}13: 00 \\
16: 00 \\
16: 00 \\
17: 00 \\
22: 00 \\
24: 00 \\
08: 00\end{array}$ & $\begin{array}{l}\text { Many very motile } \\
\text { Many very motile } \\
\text { Many motile } \\
\text { Weakly motile } \\
\text { Some motile } \\
\text { Very weakly motile }\end{array}$ & $\begin{array}{l}\overline{\overline{1 / 2}} \\
\overline{1 / 3} \\
\text { Present } \\
\text { Present } \\
\text { None }\end{array}$ & \begin{tabular}{l}
\multicolumn{1}{c}{-} \\
Many paired \\
Many paired, some separating \\
None paired $\ddagger$
\end{tabular} \\
\hline
\end{tabular}

* One ovum found in histological sections of oviduct.

$\uparrow$ Pooled result for uterine halves of oviducts; spermatozoa not detected in ovarian halves.

$\ddagger$ Oviduct not flushed.

Spermatozoa recovered from the cauda epididymidis are virtually all paired (96\%; Temple-Smith \& Bedford, 1980) and this is presumed to represent their state in the ejaculate. On the other hand, paired and single motile spermatozoa are found in the oviduct and fertilization is monospermic. Separation of paired spermatozoa was progressive, only single spermatozoa remaining in the oviduct of the female from which uterine eggs were recovered $22 \mathrm{~h}$ after 
copulation. However, the dynamics of this separation are not clear. Counts of flushed spermatozoa suggest that at the time of ovulation $30 \%$ remain paired, and by fertilization this had fallen to $6-15 \%$ (Table 1). Such figures should be regarded with some caution because single spermatozoa may be more easily flushed from the oviducal crypts and there is no quantitative estimate of the state of spermatozoa remaining in the crypts. The subjective estimates of percentage paired spermatozoa together with the histological findings (Table 1) clearly show the main point that paired spermatozoa may persist in the oviduct, even in considerable numbers, for some hours after fertilization.

Hardly any spermatozoa remained in the oviducts, sampled prior to ovulation, of the opossum that mated between 20:00 and 22:00 h on the day before ovulation (Table 1). Very few spermatozoa were present in the flushing obtained at 09:00 h and none remained in this oviduct when later examined histologically. The second oviduct was removed at 14:00 h and fixed without flushing. This contained very few spermatozoa and all were single. Mating appeared to have occurred 'too early' in this animal, for it is unlikely that such spermatozoa would have been competent to fertilize. This finding adds support to the suggestion that mating occurs as a rule early on the day of ovulation.

\section{Observations on recovered oocytes and ova}

The number of oocytes collected, the time of their recovery and fertilization status are given in Table 2. From the 10 animals in which ovulation was complete, a total of 296 ova (19-40/animal) were recovered from the oviducts $(\mathrm{N}=9)$ or uterus $(\mathrm{N}=1)$. An approximately equal number came from each ovary. Ovulation occurred between 11:00 and 17:00 h (Text-fig. 2), and most often between 12:00 and 15:00 h. Fertilization followed ovulation closely, probably around 16:00 h (Text-fig. 2). Pronucleus formation was well underway by 22:00 h (Text-fig. 2) and mature pronuclei were positioned at the centre of the ova at 24:00 h (Text-fig. 2). Mucoid deposition was advanced in ova displaying early pronuclear stages, and appeared complete in those with centrally located pronuclei although no shell was present. At 08:00 h on the day following ovulation, all embryos were found in the uterus (Text-fig. 2). Since mating had been observed in this animal at 10:00 h, $22 \mathrm{~h}$ earlier, and ovulation generally occurred between 12:00 and 15:00 h, these ova must have traversed the oviduct in 15-20 h.

\section{PLATE 1}

Fig. 1. A section of the oviducal isthmus illustrating the pseudostratified columnar epithelium lining the duct, and a sperm-containing crypt below the main epithelium. The epithelium of the main duct is formed by ciliated cells (large arrows) with large oval adluminal nuclei, and mucoid secreting cells (small arrows) with darkly stained cytoplasm (PAS) and basally located nuclei. The crypts are lined by cuboidal cells, lacking cilia and mucoid. At the far right is PAS-stained mucoid in the oviducal lumen.

Fig. 2. The isthmic crypts are joined to the oviducal lumen by a narrow opening. This crypt contains many spermatozoa, some paired. Ciliated (large arrows) and secretory (small arrows) cells of the oviducal epithelium adjacent to the crypt opening are seen at top right. The crypt is lined by cuboidal cells, with rounded nuclei. Giemsa-haematoxylin.

\section{PLATE 2}

Fig. 3. Electron micrograph of an isthmic crypt lined by cuboidal cells without cilia or obvious secretory specializations. Numerous spermatozoa are present in the lumen of the crypt, and one sperm pair is evident. Note the vacuolation of the acrosomal contents. 




(a)





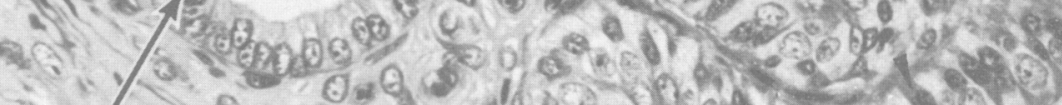

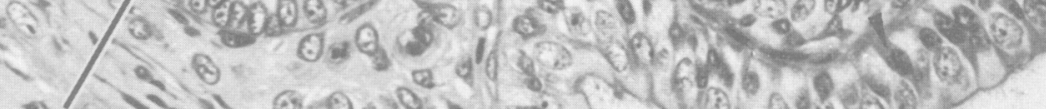

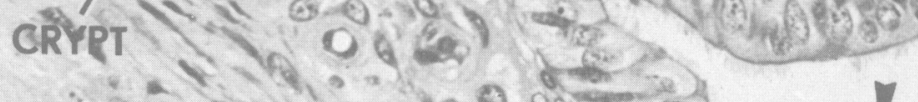

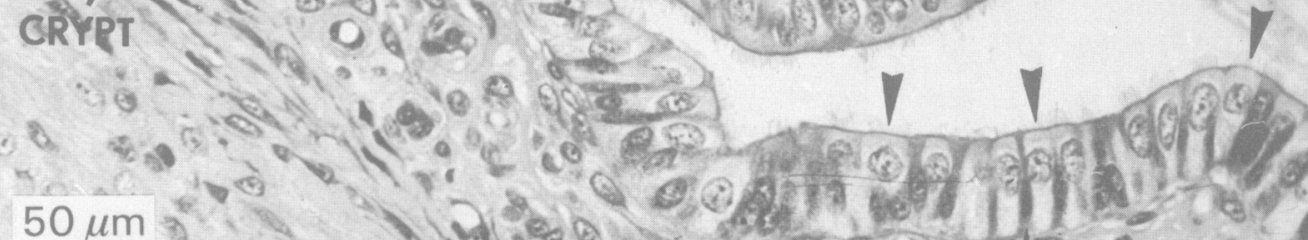

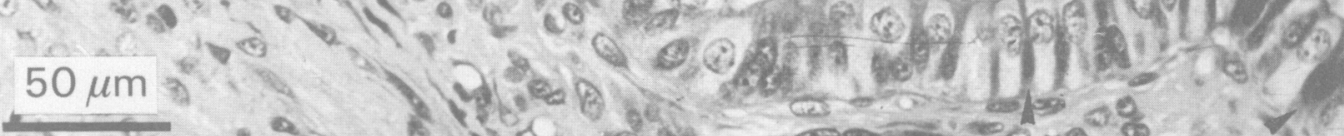

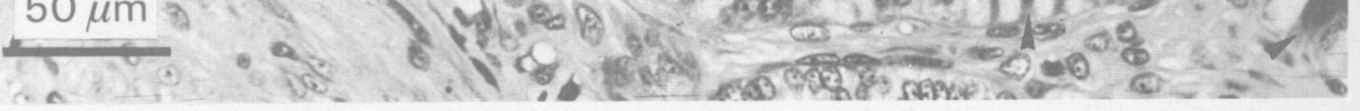

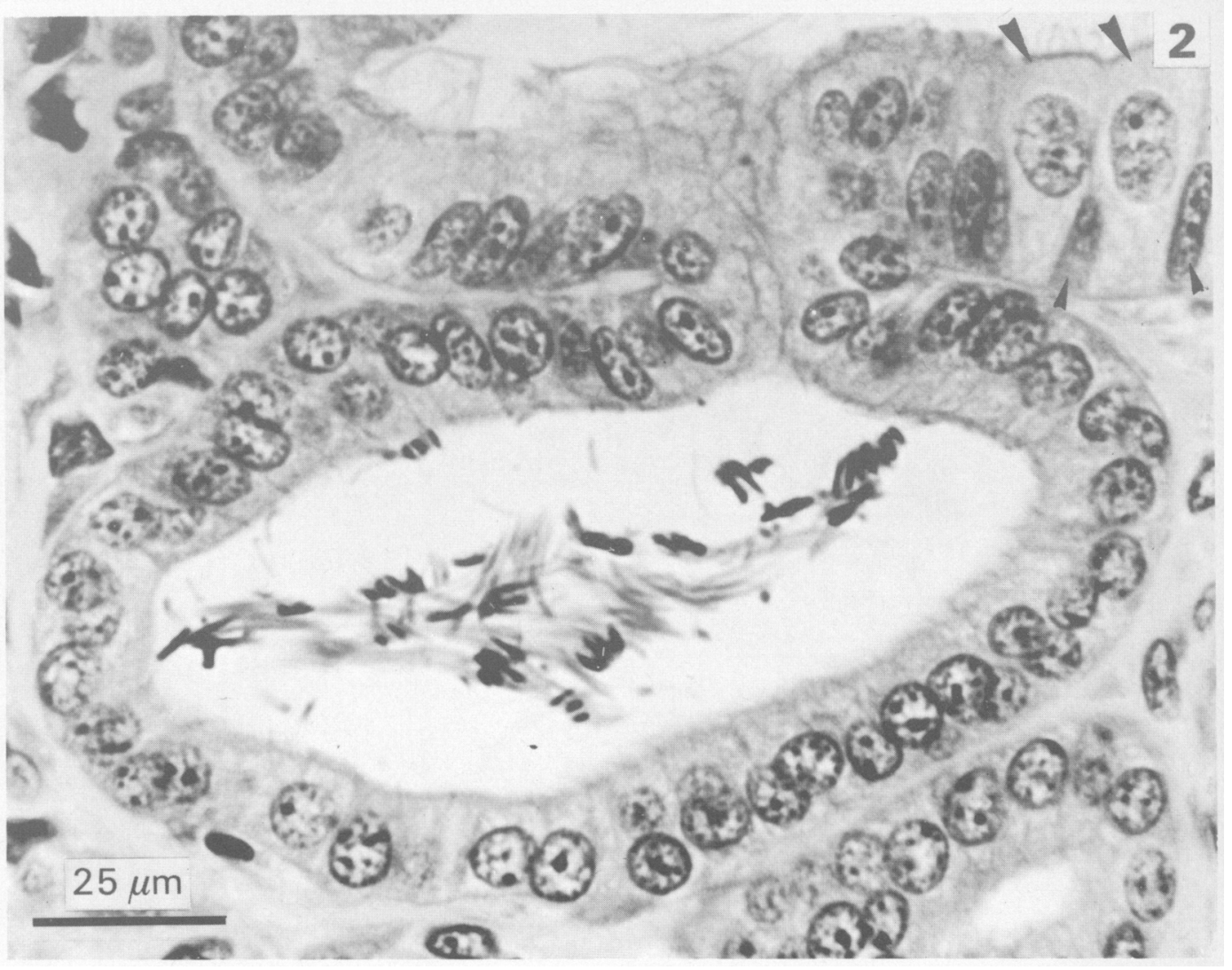

(Facing p. 164) 
PLATE 2




Table 2. Phase-contrast light microscope observations on ova recovered from the oviduct of the opossum, Didelphis virginiana

\begin{tabular}{|c|c|c|c|c|}
\hline Animal & $\begin{array}{l}\text { Time of } \\
\text { collection } \\
\text { (h) }\end{array}$ & $\begin{array}{l}\text { Site of recovery } \\
\text { (no. per side) }\end{array}$ & $\begin{array}{l}\text { Fertilization status of ova* } \\
\text { (no. examined) }\end{array}$ & Other details \\
\hline G & $11: 00$ & Oviduct $(20+20)$ & Unfertilized & Not mated \\
\hline A & $11: 00$ & Oviduct $(17+16)$ & Unfertilized (8) & $0-1$ spermatozoa on zona \\
\hline \multirow[t]{2}{*}{$\mathrm{N}$} & $12: 00$ & Oviduct (16) & Unfertilized (2) & \\
\hline & $13: 00$ & Oviduct (13) & Unfertilized (2) & \\
\hline $\mathbf{L}$ & $14: 00$ & Oviduct $(11+10)$ & Unfertilized (3) & \\
\hline $\mathbf{M}$ & $15: 00$ & $\begin{array}{l}\text { Preovulatory } \\
\text { (1 ovulation site) }\end{array}$ & - & \\
\hline $\mathbf{K}$ & $16: 00$ & Oviduct (3) & Penetrated (1) & \\
\hline D & $13: 00$ & Oviduct (7) & Unfertilized (4), penetrated (3) & $0-4$ spermatozoa on zona \\
\hline F & $16: 00$ & Oviduct $(12+13)$ & Fertilized (13) & $\begin{array}{l}\text { Very thin mucoid layer, } 2-60 \\
\text { spermatozoa on ovum }\end{array}$ \\
\hline \multirow[t]{2}{*}{ I } & $16: 00$ & Oviduct (20) & Unfertilized (1), fertilized (2) & Anaphase, thin mucoid layer \\
\hline & $17: 00$ & Oviduct (14) & Unfertilized (1), fertilized (2) & Anaphase, thin mucoid layer \\
\hline \multirow[t]{2}{*}{$\mathbf{H}$} & $17: 00$ & Oviduct (15) & Unfertilized (1), penetrated (6) & $\begin{array}{l}\text { Ooplasm bulges at penetration } \\
\text { site }\end{array}$ \\
\hline & $18: 00$ & Oviduct (15) & Unfertilized (1), fertilized (2) & Anaphase \\
\hline $\mathbf{E}$ & $22: 00$ & Oviduct $(20+17)$ & Fertilized (18) & \\
\hline B & $24: 00$ & Oviduct $(14+14)$ & Fertilized (10) & 2 pronuclei \\
\hline $\mathrm{C}$ & 08:00 & Uterus $(10+9)$ & 2-Cell (14), 1-cell (5) & \\
\hline
\end{tabular}

* 'Unfertilized' oocytes had metaphase chromosomes and one polar body. Oocytes classed as 'penetrated' had a spermatozoon attached to the oolemma by the acrosomal face of the head, or the head lay within the ooplasm. 'Fertilized' ova contained the whole fertilizing spermatozoon.

\section{Regions of the oviduct and location of the spermatozoa}

The opossum oviduct is an extended convoluted duct grossly similar to that of the rabbit, except that it is wholly U-shaped. The ovaries are not antero-lateral but are located posterior to the uterotubal junction on the dorsal aspect of the long cervices in a roughly mid-line position. The oviduct has an open extensive fimbria which covers the ovarian surface completely in periovular animals. The presence of the fimbria and the positioning of the ovaries dorsal to the uterus made their examination in situ from a mid-line abdominal (ventral) approach difficult. From the fimbria, the oviduct passes anteriorly along the dorsal aspect of the uterus for about the first two-thirds of the duct proper. It is then reflected upon itself to run posteriorly to join the tapering uterus at an ill defined uterotubal junction.

The oviduct was not divided into grossly recognizable regions other than the fimbria. A striking regional organization was evident, however, when the duct was examined in the light and electron microscope. Along the entire length of the oviduct, its epithelium was formed by both ciliated and non-ciliated cells (PI. 1, Figs 1 and 2). In the fimbria and infundibulum, the epithelium was cuboidal to low columnar and the non-ciliated cells gave no or only weak evidence of secretory activity, as judged by staining reactions with the mucopolysaccharide histochemical techniques. The region equivalent to the ampulla made up the main portion of the oviduct to about the point of flexure, the mucosa was highly folded and the epithelium tall columnar-pseudostratified. The supranuclear cytoplasm of the non-ciliated cells in this ampullary region was filled with mucopolysaccharide secretory granules (PAS- and alcian blue-positive, gamma metachromatic with toluidine blue) and material with identical staining properties was found in the oviducal lumen. Secretory activity, as detected by these histochemical methods, decreased considerably in the isthmic portion of the oviduct so that, in the last centimetre above the uterotubal junction, no mucoid secretory product was discernible in the non-ciliated cells. The lumen of the isthmus was far less arborized than in the ampulla and the muscle coat was more pronounced. 
The isthmus was distinguished especially from the ampulla by cryptic pockets which communicated with the lumen via narrow openings (Pl. 1, Fig. 2). These crypts were lined by cuboidal to low columnar cells, ciliated cells were absent and there was no evidence of mucoid secretion. Many of the crypts contained spermatozoa that were paired, single or separating (Table 1, Pl. 2, Fig. 3). Only the occasional spermatozoon was found outside the crypts in the oviducal lumen, whether or not the oviduct had been flushed prior to fixation.

\section{Discussion}

Mating of opossums at the oestrus after removal of a sucking litter proved highly successful in the conditions of a laboratory animal house. The relative ease with which this was achieved should not be taken to indicate that a self-sustaining breeding colony could be maintained in this way, for such a colony has only been achieved with close management under semi-natural conditions (Jurgelski et al., 1974). In the present study, the opossums were housed in stainless-steel cages, fed a laboratory diet, and exposed to a 12-h artificial light schedule. Only for actual mating were animals placed in a special cage. Its relatively elongated shape allowed the animals to avoid close contact when the female was unreceptive, and fighting or injury never occurred.

An essentially similar pattern between the age of a litter at its removal and the time to the resulting oestrus (Text-fig. 1) has been demonstrated for bandicoots Perameles nasuta (Close, 1977; A. G. Lyne, personal communication). In a breeding colony of bandicoots when young less than 6 days of age were removed oestrus occurred about 20 days later, as judged by the age of the resulting litter. If the young were greater than 10 days old the return to oestrus took only 7 days (Close, 1977). Similarly, in opossums, the period to oestrus was significantly extended if young were removed within $24 \mathrm{~h}$ of birth (Feldman \& Ross, 1975). The present study is, however, the first to our knowledge to demonstrate that this apparent trend represents a statistically significant correlation. The finding is of considerable practical value because the regression line (Text-fig. 1) in combination with the data in Text-fig. 2 makes possible a reasonably accurate prediction of the time at which mating and subsequent fertilization events will occur.

When allowed free access, opossums generally mated between 24:00 and 06:00 h. As ovulation follows between $12: 00$ and $13: 00 \mathrm{~h}$, the potential fertile oestrous period is probably somewhat shorter than $12 \mathrm{~h}$. Copulation, when observed, lasted $20 \mathrm{~min}$ with apparent periods of rest during coitus. These findings on the length of oestrus and the duration of copulation are in line with observations in other polyoestrous marsupials, in which as a rule the receptive period lasts up to $12 \mathrm{~h}$ and copulation at most only minutes (Sharman, 1955a; b; Sharman \& Pilton, 1964; Sharman \& Calaby, 1964; Stodart, 1966). Not all marsupials, however, have such a restricted oestrus. The rat kangaroo, Potorous, although a macropodid marsupial, departs from the pattern in that oestrus lasts up to 12 days, but the repeated copulations are brief ( 2 min: Hughes, 1962). In the monoestrous marsupials, Antechinus (Marlowe, 1961) and Dasyurus (Hill \& O'Donoghue, 1913; Weber, 1974), the female experiences oestrus lasting several days and prolonged copulation, lasting hours, may occur on each of these days. The time to ovulation seems to be variable (Hill \& O'Donoghue, 1913).

In polyoestrous marsupials, ovulation generally follows closely after mating in a regular manner. Ovulation in opossums is particularly marked in this respect, occurring some $12-15 \mathrm{~h}$ after copulation. In the macropodids and the brush possum, Trichosurus, ovulation is generally expected within 1-2 days of the start of oestrus (Sharman, 1955b; Hughes, 1962; Pilton \& Sharman, 1962; Godfrey, 1969; Shorey \& Hughes, 1975). The timing of ovulation in certain of these earlier studies may be imprecise, as observation of fertilization events was not the main 
intention. However, timing of sperm transport and ovulation in the tammar wallaby confirms the accepted pattern, with ovulation occurring 20-24 h after mating (Tyndale-Biscoe \& Rodger, 1978). Ovulation in opossums is spontaneous, as in all marsupials examined directly (Sharman, 1959; Hughes \& Shorey, 1973), although histological examination of preserved ovaries suggests that ovulation may be induced by coitus in an unspecified didelphid (Martinez-Esteve, 1937) and the tree kangaroo (Dendrolagus: Matthews, 1947).

In accord with the pattern seen in many eutherian mammals (Austin \& Braden, 1954; Austin \& Walton, 1960), ovulation in the opossum occurred over a relatively restricted period of 2-4 h. Fertilization followed closely thereafter, with penetration beginning in some cases before all ova were released (Table 2; Text-fig. 2). That fertilization is an early event in the opossum is presumably related to mucoid deposition on the surface of the zona pellucida, for in many ova in which incorporation of the penetrating spermatozoon into the vitellus was incomplete, mucoid deposition had begun. This is in contrast to events in the rabbit, in which mucoid is not released from the oviducal epithelium until $10-12 \mathrm{~h}$ after ovulation (Greenwald, 1958).

The longevity of marsupial spermatozoa in the female has received little attention since it was established that the mechanism of delayed birth in macropodids was not related to sperm storage and delayed fertilization but to embryonic diapause (Sharman, 1955b). As in other marsupials (Sharman, 1955a, b; Hughes, 1962) highly motile spermatozoa are not found in the female opossum tract long after fertilization, and indeed spermatozoa are found only rarely in the oviducts $24 \mathrm{~h}$ after mating. Degenerate spermatozoa persist in the vaginal complex for 1-2 days, and in bandicoots intact but dead spermatozoa remain trapped in the matrix material of the vaginal caecae through the ensuing pregnancy and into early lactation (Hughes, 1962: Lyne, 1976). In contrast, motile spermatozoa may remain in the oviduct of Antechinus and Dasyurus for a number of days after copulation, as much as 2 weeks for Dasyurus (Hill \& O'Donoghue, 1913; Woolley, 1966).

The finding that opossum spermatozoa separate before fertilization is not surprising. Pairing appears to be restricted to the period of sperm transport to the oviducal isthmus. Whether the crypts in the oviduct have an active role in the process of separation is not known. Apparently normal sperm separation has been observed in fresh oviducal flushings, and paired epididymal spermatozoa tend to separate if incubated in vitro at $37^{\circ} \mathrm{C}$ for $2-4 \mathrm{~h}$ (J. C. Rodger \& J. M. Bedford, unpublished), but it is not known if this latter case represents a degenerative or functional event.

Epithelial crypts or other marked regionality of the oviduct have not previously been described in marsupials. Regions of sperm receptacles or glands are a common feature of the vertebrate female tract, and these are often the site of sperm storage for extended periods (Thibault, 1973). The opossum appears to be the only animal so far described to have specialized oviducal sperm crypts in the absence of such storage. No such feature was found in the tammar wallaby (Tyndale-Biscoe \& Rodger, 1978), or in the general description of oviduct morphology in Australian marsupials provided by Hughes \& Shorey (1973). A similar region may exist in Dasyurus, because large bunches of spermatozoa were found in "gland lumina" opening into the oviduct by Hill \& O'Donoghue (1913). In all other respects, the form of the opossum oviduct and the staining properties of its mucoid secretion are in general terms identical to those described for Australian marsupials (Hughes \& Shorey, 1973; Hughes, 1977).

Oviducal transport of opossum ova has been known to be relatively rapid compared to that in eutherians since the early experimental study of Hartman (1924a), in which nematode (Ascaris) eggs were used as markers. The data obtained here suggest that the period of ovum transit in marsupials is even shorter $(15-20 \mathrm{~h})$ than the $24 \mathrm{~h}$ maximum which Hartman suggested, which is still generally accepted as valid for all marsupials (Renfree \& Tyndale-Biscoe, 1978; Sutherland, Evans \& Tyndale-Biscoe, 1980). 
We thank Miu Ying Fong for her skilled technical assistance in this study. The work was primarily supported financially by a grant to J.M.B. from the Needmor Fund and also by NIH grant, HD-07257. J.C.R. has been the recipient of a CSIRO post-doctoral studentship.

\section{References}

Austin, C.E. \& Braden, A.W.H. (1954) Time relations and their significance in the ovulation and penetration of eggs in rats and rabbits. Aust. J. biol. Sci. 7, 179-194.

Austin, C.E. \& Walton, A. (1960) Fertilisation. In Marshall's Physiology of Reproduction, 3rd edn, vol. 1, part 2, pp. 310-416. Ed. A. S. Parkes. Longmans Green, London.

Bedford, J.M. (1971) Techniques and criteria used in the study of fertilization. In Methods in Mammalian Embryology, pp. 37-63. Ed. J. C. Daniel. Freeman, San Francisco.

Bishop, O.N. (1971) Statistics for Biology, 2nd edn. Longmans, London.

Chang, M.C. (1952) Fertilizability of rabbit ova and the effects of temperature in vitro on their subsequent fertilization and activation in vivo. J. exp. Zool. 121, 35 1-382.

Close, R.L. (1977) Recurrence of breeding after cessation of suckling in the marsupial Perameles nasuta. Aust. J. Zool. 25, 641-645.

Cummins, J.M. (1976) Epididymal maturation of spermatozoa in the marsupial Trichosurus vulpecula: changes in motility and gross morphology. Aust. J. Zool. 24, 499-511.

Feldman, D.B. \& Ross, P.W. (1975) Methods for obtaining neonates of known age from the Virginia opossum (Didelphis marsupialis virginiana). Lab. Anim. Sci. 25, 437-439.

Godfrey, G.K. (1969) Reproduction in a laboratory colony of the marsupial mouse Sminthopsis larapinta (Marsupialia: Dasyuridae). Aust. J. Zool. 17, 637-654.

Greenwald, G.S. (1958) Endocrine regulation of the secretion of mucin in the tubal epithelium of the rabbit. Anat. Rec. 130, 477-495.

Harding, H.R., Carrick, F.N. \& Shorey, C.D. (1976) Ultrastructural changes in the spermatozoa of the brush-tailed possum, Trichosurus vulpecula (Marsupialia), during epididymal transit. Cell Tiss. Res. 171, 61-73.

Harding, H.R., Carrick, F.N. \& Shorey, C.D. (1979) Special features of sperm structure and function in marsupials. In The Spermatozoon, pp. 289-303. Eds D. W. Fawcett \& J. M. Bedford. Urban \& Schwarzenberg, Baltimore.

Hartman, C.G. (1916) Studies in the development of the opossum: Didelphys virginiana L. 1. History of early cleavage. II. Formation of the blastocyst. J. Morph. $27,1-83$.

Hartman, C.G. (1919) Studies in the development of the opossum (Didelphys virginiana L.) III. Description of new material on maturation, cleavage, and entoderm formation. IV. The bilaminar blastocyst. $J$. Morph. 32, 1-42.
Hartman, C.G. (1924a) Observations on the viability of the mammalian ovum. Am. J. Obstet. Gynec. 7, 40-43.

Hartman, C.G. (1924b) Observations on the motility of the opossum genital tract and the vaginal plug. Anat. Rec. 27, 293-303.

Hill, J.P. (1910) The early development of the Marsupialia, with special reference to the native cat (Dasyurus viverrinus). Q. Jl microsc. Sci. 56, 1-134.

Hill, J.P. \& O'Donoghue, C.H. (1913) The reproductive cycle in the marsupial Dasyurus viverrinus. $Q$. $J l$ microsc. Sci. 59, 133-174.

Hughes, R.L. (1962) Reproduction in the macropod marsupial Potorous tridactylus (Kerr). Aust. J. Zool. 10, 193-224.

Hughes, R.L. (1977) Egg membranes and ovarian function during pregnancy in monotremes and marsupials. In Reproduction and Evolution, pp. 281-291. Eds J. H. Calaby \& C. H. Tyndale-Biscoe. Australian Academy of Science, Canberra.

Hughes, R.L. \& Shorey, C.D. (1973) Observations on the permiability properties of the egg membranes of the marsupial Trichosurus vulpecula. J. Reprod. Fert. 32, 25-32.

Jurgelski, W. (1974) The opossum (Didelphis virginiana Kerr) as a biomedical model. I. Research perspective, husbandry, and laboratory technics. Lab. Anim. Sci. 24, 376-403.

Jurgelski, W. \& Porter, M.E. (1974) The opossum (Didelphis virginiana Kerr) as a biomedical model. III. Breeding the opossum in captivity: methods. Lab. Anim. Sci. 24, 412-425.

Jurgelski, W., Forsythe, w., Dahl, D., Thomas, L.D., Moore, J.A., Kotin, P., Falk, H.L. \& Vogel, F.S. (1974) The opossum (Didelphis virginiana Kerr) as a biomedical model. II. Breeding the opossum in captivity: facility design. Lab. Anim. Sci. 24, 404-411.

Lintern-Moore, S. \& Moore, G.P.M. (1977) Comparative aspects of oocyte growth in mammals. In Reproduction and Evolution, pp. 215-219. Eds J. H. Calaby \& C. H. Tyndale-Biscoe. Australian Academy of Science, Canberra.

Lintern-Moore, S., Moore, G.P.M., Tyndale-Biscoe, C.H. \& Poole, W.E. (1976) The growth of the oocyte and follicle in the ovaries of monotremes and marsupials. Anat. Rec. 185, 325-331.

Lyne, A.G. (1976) Observations on oestrus and the oestrous cycle in the marsupials Isoodon macrourus and Perameles nasuta. Aust.J. Zool. 24, 513-521.

Marlowe, B.J. (1961) Reproductive behaviour of the marsupial mouse. Antechinus flavipes (Waterhouse) (Marsupialia) and the development of the pouch young. Aust. J. Zool. 8, 203-218.

Martinez-Esteve, P. (1937) Le cycle sexuel vaginal chez 
le marsupial Didelphys azarae. C. r. Séanc. Soc. Biol. 124, 502-504.

Matthews, L.H. (1947) A note on the female reproductive tract of the tree kangaroos (Dendrolagus). Proc. zool. Soc. Lond. 117, 313-333.

New, D.A.T. \& Mizell, M. (1972) Opossum fetuses grown in culture. Science, N.Y. 75, 533-535.

New, D.A.T., Mizell, M. \& Crockroft, D.L. (1977) Growth of opossum embryos in vitro during organogenesis. J. Embryol. exp. Morph. 41, 111123.

Olson, G.E. (1975) Observations on the ultrastructure of a fibre network in the flagellum of sperm of the brush-tailed phalanger, Trichosurus vulpecula. J. Ultrastruct. Res. 50, 193-198.

Olson, G.E. (1980) Changes in intramembranous particle distribution in the plasma membrane of Didelphis virginiana spermatozoa during maturation in the epididymis. Anat. Rec. 197, 471-488.

Olson, G.E. \& Hamilton, D.W. (1976) Morphological changes in the midpiece of woolly opossum spermatozoa during epididymal transit. Anat. Rec. 186 , $387-404$.

Pearse, A.G.E. (1968) Histochemistry, Theoretical and Applied, 3rd edn, vol. 1. Williams and Wilkins, Baltimore.

Phillips, D.M. (1970) Ultrastructure of spermatozoa of the woolly opossum Caluromys philander. $J$. Ultrastruct. Res. 33, 381-397.

Pilton, P.E. \& Sharman, G.B. (1962) Reproduction in the marsupial Trichosurus vulpecula. J. Endocr. 25, 119-136.

Renfree, M.B. (1974) Ovariectomy during gestation in the American opossum, Didelphis marsupialis virginiana. J. Reprod. Fert. 39, 127-130.

Renfree, M.B. \& Tyndale-Biscoe, C.H. (1978) Manipulation of marsupial embryos and pouch young. In Methods in Mammalian Reproduction, pp. 307-331. Ed. J. C. Daniel. Academic Press, New York.

Reynolds, H.D. (1952) Studies on reproduction in the opossum (Didelphis virginiana). Univ. Calif. Publ. Zool. 52, 223-284.

Rodger, J.C. \& Bedford, J.M. (1982) Separation of sperm pairs and sperm-egg interaction in the opossum, Didelphis virginiana. J. Reprod. Fert. 64, 171-179.

Sharman, G.B. (1955a) Studies in marsupial reproduction. II. The oestrous cycle of Setonix brachyurus. Aust. J. Zool. 3, 44-55.
Sharman, G.B. (1955b) Studies in marsupial reproduction. III. Normal and delayed pregnancy in Setonix brachyurus. Aust. J. Zool. 3, 56-70.

Sharman, G.B. (1959) Marsupial reproduction. In Biogeography and Ecology in Australia, pp. 332368. Eds A. Keast, R. L. Crocker \& C. S. Christian. Junk, Den Haag.

Sharman, G.B. \& Calaby, J.H. (1964) Reproductive behaviour in the red kangaroo, Megaleia rufa, in captivity. CSIRO Wildlife Res. 9, 58-85.

Sharman, G.B. \& Pilton, P.E. (1964) The life history and reproduction of the red kangaroo (Megaleia rufa). Proc. zool. Soc. Lond. 142, 29-48.

Shorey, C.D. \& Hughes, R.L. (1975) Uterine response to ovariectomy during the proliferative and luteal phases in the marsupial. Trichosurus vulpecula. $J$. Reprod. Fert. 42, 221-228.

Stodart, E. (1966) Management and behaviour of breeding groups of the marsupial Perameles nasuta Geoffrey in captivity. Aust. J. Zool. 14,611-623.

Sutherland, R.L., Evans, S.M. \& Tyndale-Biscoe, C.H. (1980) Macropodid marsupial luteinizing hormone: validation of assay procedures and changes in concentrations in plasma during the oestrous cycle in the female tammar wallaby (Macropus eugenii). $J$. Endocr. 86, 1-12.

Temple-Smith, P.D. \& Bedford, J.M. (1976) The features of sperm maturation in the epididymis of a mar supial, the brushtailed possum Trichosurus vulpecula. Am. J. Anat. 147, 471-500.

Temple-Smith, P.D. \& Bedford, J.M. (1980) Sperm maturation and the formation of sperm pairs in the epididymis of the opossum, Didelphis virginiana. $J$. exp. Zool. 214, 161-171.

Thibault, C.G. (1973) Sperm transport and storage in vertebrates. J. Reprod. Fert., Suppl. 18, 39-53.

Tyndale-Biscoe, C.H. \& Rodger, J.C. (1978) Differential transport of spermatozoa into the two sides of the genital tract of a monovular marsupial, the tammar wallaby (Macropus eugenii). J. Reprod. Fert. 52, 37-43.

von Korph, K. (1902) Zur histogenese der spermien von Phalangista vulpina. Arch. Mikrosk. Anat. 60, 232-260.

Weber, E. (1974) Breeding the eastern native-cat, Dasyurus viverrinus, at Melbourne Zoo. Int. Zoo. Yb. 14, 106-107.

Woolley, P. (1966) Reproductive biology of Antechinus stuartii Macleay (Marsupialia: Dasyuridae). Ph.D. thesis, Aust. Nat. Univ., Canberra.

Received 13 April 1981 